\title{
Acute kidney injury following major emergency abdominal surgery - a retrospective cohort study based on medical records data
}

\author{
Theis B. Mikkelsen* ${ }^{*}$, Anders Schack, Jakob O. Oreskov, Ismail Gögenur, Jakob Burcharth and Sarah Ekeloef
}

\begin{abstract}
Background: Acute Kidney Injury (AKI) is a frequent and serious postoperative complication in trauma or critically ill patients in the intensive care unit. We aimed to estimate the risk of AKI following major emergency abdominal surgery and the association between AKI and 90-day postoperative mortality.

Methods: In this retrospective cohort study, we included patients undergoing major emergency abdominal surgery at the Department of Surgery, Zealand University Hospital, Denmark, from 2010 to 2016. The primary outcome was the occurrence of AKI within postoperative day seven (POD7). AKI was defined according to the Kidney Disease: Improving Global Outcomes (KDIGO)-criteria. The risk of AKI was analysed with a multivariable logistic regression. The association between AKI and 90-day mortality was analysed with a multivariable survival analysis.
\end{abstract}

Results: In the cohort, 122 out of 703 (17.4\%) surgical patients had AKI within POD7. Of these, 82 (67.2\%) had AKI stage 1, 26 (21.3\%) had AKI stage 2, and 14 (11.5\%) had AKI stage 3. Fifty-eight percent of the patients who developed postoperative AKI did so within the first $24 \mathrm{~h}$ of surgery. Ninety-day mortality was significantly higher in patients with AKI compared with patients without AKI (41/122 (33.6\%) versus 40/581 (6.9\%), adjusted hazard ratio 4.45 (95\% confidence interval 2.69-7.39, $P<0.0001)$ ), and rose with increasing KDIGO stage. Pre-existing hypertension and intraoperative peritoneal contamination were independently associated with the risk of AKI.

Conclusions: The risk of AKI is high after major emergency abdominal surgery and is independently associated with the risk of death within 90 days of surgery.

Keywords: Abdominal surgery, Acute kidney injury, Intensive care, Postoperative complications, Emergency surgery

\section{Background}

Acute kidney injury (AKI) is a frequent but often overlooked complication after major surgery [1-3]. The incidence ranges from 22 to $40 \%$ depending on the population and type of surgery [4-6]. Postoperative AKI has been found to increase the risk of subsequent morbidity and mortality in patients undergoing major elective surgery and in critically ill patients in the intensive care unit

*Correspondence: theismikkelsen92@gmail.com

Center for Surgical Science, Department of Surgery, Zealand University

Hospital, Lykkebaekvej 1, 4600 Koege, Denmark
$[1,2]$. The pathophysiology of AKI in relation to surgery is not fully understood, making it challenging to prevent. Ischemia, inflammation, oxidative stress, and genetics might be central factors included in the pathophysiology of postoperative AKI $[7,8]$. Clinical risk factors include pre-existing chronic kidney disease, diabetes, advanced age and hypertension [2, 5, 6, 9]. A number of different systems for classification and diagnosis of AKI have been introduced over the years. Today, the predominant method is the Kidney Disease: Improving Global Outcomes (KDIGO)-criteria [10], where AKI is defined as an abrupt decrease in renal function and AKI can clinically 
be identified as a rise in s-creatinine levels and decreasing urine outputs [11].

The risk of postoperative complications and subsequent morbidity is high in patients undergoing major emergency abdominal surgery [12,13]. Several organs are affected by the underlying pathology and the surgical stress response leading to an increased risk of perioperative single and multiorgan dysfunction [14]. Therefore, national and regional initiatives have in recent years been implemented in order to improve the clinical outcomes for this specific surgical population [15-17]. The risk and consequences of AKI are well known after major elective surgery and in critically ill surgical patients in the intensive care unit, however, no specific focus has been on AKI after major emergency abdominal surgery where the majority of the patients are treated in the general surgical ward postoperatively.

The aim of this retrospective cohort study was to estimate the risk of AKI following major emergency abdominal surgery and evaluate whether AKI is associated with 90-day postoperative mortality after emergency surgery.

\section{Methods}

\section{Study design and setting}

We conducted a retrospective cohort study reported according to The Strengthening the Reporting of Observational Studies in Epidemiology (STROBE) Statement [18]. We included patients who underwent major emergency abdominal surgery at Department of Surgery, Zealand University Hospital (Denmark) from January 2010 through September 2016.

The study was approved by the Danish Data Protection Agency (approval: REG-010-2017). In Denmark, a written informed consent and ethical approval are by law not necessary for retrospective database studies. Authors had full access to all data.

\section{Study population}

All patients from the age of 18 undergoing major emergency (within $72 \mathrm{~h}$ of admission) abdominal surgery were included. Surgical procedures involving the stomach, small or large bowel, or rectum for conditions such as perforation, ischaemia, abdominal abscess, bleeding or obstruction, washout/evacuation of intra-peritoneal haematoma or abscess, laparotomy/laparoscopy with inoperable pathology (e.g., peritoneal/hepatic metastases), adhesiolysis, fascial dehiscence or any reoperation meeting the criteria above were included. Laparoscopic as well as open procedures were included if adherent to procedure-criteria. Patients who subsequently underwent several surgical procedures were eligible for inclusion if the primary procedure was includable. Patients who underwent minor abdominal procedures (appendectomy and cholecystectomy) as the sole surgical procedure were excluded. Trauma surgery was excluded due to the different pathophysiology. End-stage renal disease with dialysis or kidney transplantation were not exclusion criteria.

AKI was defined according to the KDIGO criteria [10]. The baseline s-creatinine level was defined as the s-creatinine level at admission. If multiple preoperative values were available from admission to the day of surgery, the highest value was chosen as baseline. Patients with no pre- or postoperative creatinine value were excluded. Postoperatively, patients were transferred to the standard surgical ward. However, patients in need of respiratory or cardiovascular support were transferred directly to the ICU. This decision was made by the attending anesthesiologist and/or surgeon.

As a standard, all patients received intravenous piperacillin-tazobactam on postoperative day one to three. Only patients that were admitted to the intensive care unit postoperatively were treated with vasoactive drugs.

\section{Data collection}

Retrospectively, patients were included using NOMESCO-based procedure codes (Additional file 1). All patient data were collected from individual electronic patient records. This included: patient demographics, pre-, intra- and postoperative data, American Association of Anaesthesiologists classification (ASA-classification), WHO performance score, quick Sequential Organ Failure Assessment (qSOFA) at admission, and biochemical data (s-creatinine, estimated glomerular filtration rate (eGFR), blood urea, p-haemoglobin, p-sodium, p-potassium). The investigators calculated the Charlson Comorbidity Index (CCI) [19] based on ICD-codes available in the electronic patient records. The investigators evaluated the surgical complications by Clavien-Dindo score.

In Denmark, the vital status of all citizens is registered in the Danish Civil Registration System. This national registry is automatically linked with the electronic patient record. Data on 90-day mortality were extracted from the electronic patient record.

\section{Outcomes}

The primary outcome was the incidence of postoperative AKI within seven days of surgery. Furthermore, the level of AKI was staged from 1 to 3 . Postoperative AKI Stage 1 was according to the KDIGO criteria [10] defined as a 1.5-1.9-fold increase in s-creatinine level from baseline or an absolute $26.5 \mu \mathrm{mol} \mathrm{l}^{-1}$ increase in $\mathrm{s}$-creatinine level over a period of $48 \mathrm{~h}$ or less within seven days of surgery. AKI Stage 2 was defined as a 2.0-2.9-fold increase in postoperative s-creatinine, and AKI Stage 3 as $a \geq$ threefold increase of postoperative s-creatinine from baseline or an absolute increase 


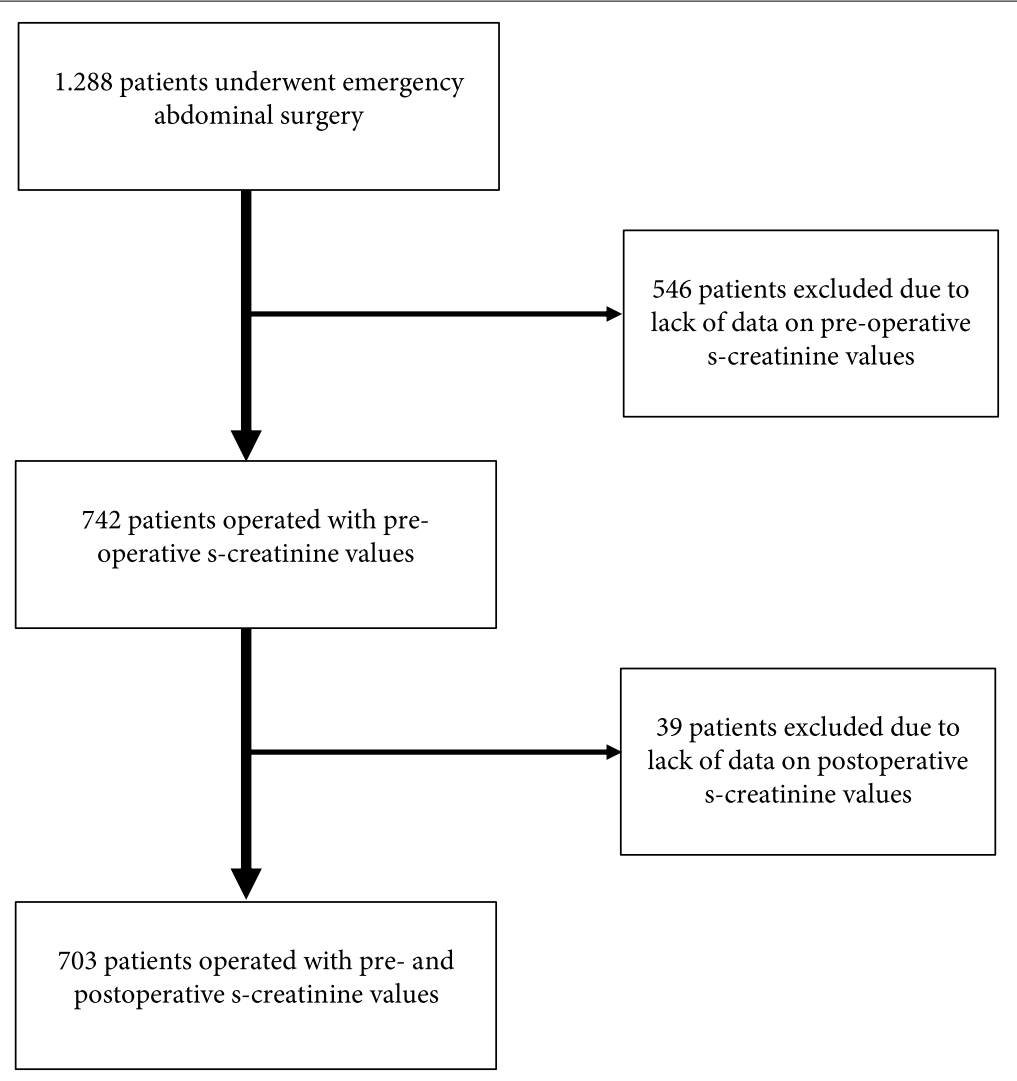

Fig. 1 Patient flow

in $\mathrm{s}$-creatinine to $\geq 353.6 \mu \mathrm{mol} \mathrm{l} \mathrm{l}^{-1}$, both over a period of $48 \mathrm{~h}$ or less within seven days of surgery. The binary primary outcome, postoperative AKI, was defined by the first elevated s-creatinine according to the KDIGO definition over a period of $48 \mathrm{~h}$ or less within seven days of surgery, whereas the grading of AKI (1-3) was based on the largest increase in s-creatinine over a period of 48 -h or less within seven days of surgery. Secondary outcomes included 90-day mortality, intensive care unit (ICU) admission, lengths of stay, and surgical complications defined as a Clavien-Dindo score $\geq 3$ [20].

\section{Statistical analysis}

The population was stratified into patients with and without AKI ( $\geq$ KDIGO stage 1 ). Data distribution was examined with histograms and QQ-plots. Continuous data were presented as means with standard deviation (SD) or medians with interquartile range (IQR). Categorical data were presented as proportions and percentages. Categorical data were analysed using $X$ [2]-test or Fischer's exact test as appropriate. Continuous data were analysed using student's unpaired t-test or the Mann-Whitney $U$ test. The difference in s-creatinine over time stratified on AKI was analysed with a mixed model with an unstructured variance-covariance structure. We performed a uni- and multivariable logistic regression by forced entry method to identify variables associated with the risk of postoperative AKI. Predefined independent variables included age group, sex, performance score, congestive heart failure, baseline s-creatinine, hypertension, diabetes, peritoneal contamination, intraoperative blood loss, and qSOFA. The variables were selected on the basis of clinical hypotheses and previous studies on postoperative AKI [21-23]. Results were expressed as unadjusted and adjusted odds ratios (OR) with $95 \%$ confidence interval (95\% CI). The fitting of the model was tested with the Hosmer and Lemeshow Goodness of Fit test. Uni- and multivariable survival analysis on the association between AKI and 90-day postoperative mortality was performed. Predefined variables included in the analysis: AKI, baseline s-creatinine, age group, sex, CCI, type of surgical procedure, peritoneal contamination, and qSOFA. The model was adjusted for potential immortal time bias. The survival analysis fulfilled the proportional hazards assumption. Results were expressed as unadjusted and 
Table 1 Demographical characteristics

\begin{tabular}{|c|c|c|c|c|}
\hline & Total $(n=703)$ & $\begin{array}{l}\text { Patients without acute } \\
\text { kidney injury }{ }^{\mathrm{a}}(n=581)\end{array}$ & $\begin{array}{l}\text { Patients with acute } \\
\text { kidney injury }{ }^{\mathrm{a}}(n=122)\end{array}$ & $\begin{array}{l}P \text {-value (acute kidney injury } \\
\text { versus no acute kidney } \\
\text { injury }^{\mathrm{a}} \text { ) }\end{array}$ \\
\hline Age (years) & & & & $<0.0001$ \\
\hline 60 & $240(34.1 \%)$ & $224(38.6 \%)$ & $16(13.1 \%)$ & \\
\hline$>60-70$ & $176(25.0 \%)$ & $138(23.8 \%)$ & $38(31.1 \%)$ & \\
\hline$>70-80$ & $160(22.8 \%)$ & $128(22.0 \%)$ & $32(26.2 \%)$ & \\
\hline$>80$ & $127(18.1 \%)$ & 91 (15.7\%) & $36(29.5 \%)$ & \\
\hline Female & $384(54.6 \%)$ & $319(54.9 \%)$ & $65(53.3 \%)$ & 0.74 \\
\hline Active smoking & $144(21.1 \%)$ & $109(19.3 \%)$ & 35 (29.7\%) & 0.01 \\
\hline Missing & $20(2.8 \%)$ & $16(2.8 \%)$ & $4(3.3 \%)$ & \\
\hline Excessive alcohol use ${ }^{b}$ & $71(10.1 \%)$ & $59(10.2 \%)$ & $12(9.8 \%)$ & 0.92 \\
\hline $\mathrm{ASA}^{\mathrm{c}}$ & & & & 0.004 \\
\hline$|-| \mid$ & $464(70.9 \%)$ & $397(73.2 \%)$ & $67(59.8 \%)$ & \\
\hline$\geq I I I$ & $190(29.1 \%)$ & $145(26.8 \%)$ & $45(40.2 \%)$ & \\
\hline Missing & $49(7.0 \%)$ & $39(6.7 \%)$ & $10(8.2 \%)$ & \\
\hline Performance score & & & & 0.03 \\
\hline 0 & $487(72.0 \%)$ & $412(74.2 \%)$ & 75 (62.0\%) & \\
\hline 1 & $143(21.2 \%)$ & $108(19.5 \%)$ & 35 (28.9\%) & \\
\hline$\geq 2$ & $46(6.8 \%)$ & $35(6.3 \%)$ & $11(9.1 \%)$ & \\
\hline Missing & $27(3.8 \%)$ & $26(4.5 \%)$ & $1(0.8 \%)$ & \\
\hline qSOFA $^{d}$ & & & & 0.02 \\
\hline 0 & $258(43.3 \%)$ & $227(45.6 \%)$ & $31(31.6 \%)$ & \\
\hline 1 & $284(47.7 \%)$ & $231(46.4 \%)$ & $53(54.1 \%)$ & \\
\hline$\geq 2$ & $54(9.1 \%)$ & $40(8.0 \%)$ & $14(14.3 \%)$ & \\
\hline Missing & $107(15.2 \%)$ & $83(14.3 \%)$ & $24(19.7 \%)$ & \\
\hline Chronic Kidney Disease & $30(4.3 \%)$ & $25(4.3 \%)$ & $5(4.1 \%)$ & 0.92 \\
\hline Hypertension & $314(44.7 \%)$ & $228(39.2 \%)$ & $86(70.5 \%)$ & $<0.0001$ \\
\hline Diabetes & $74(10.5 \%)$ & $53(9.1 \%)$ & $21(17.2 \%)$ & 0.008 \\
\hline Ischaemic Heart Disease & $72(10.2 \%)$ & $55(9.5 \%)$ & $17(13.9 \%)$ & 0.14 \\
\hline Heart Failure & $34(4.8 \%)$ & $26(4.5 \%)$ & $8(6.6 \%)$ & 0.33 \\
\hline COPD $^{f}$ & $104(14.8 \%)$ & $85(14.6 \%)$ & $19(15.6 \%)$ & 0.79 \\
\hline Cerebrovascular Disease & $53(7.5 \%)$ & $44(7.6 \%)$ & $9(7.4 \%)$ & 0.94 \\
\hline Charlson Comorbidity Index & & & & $<0.0001$ \\
\hline 0 & $324(46.1 \%)$ & $279(48.0 \%)$ & $45(36.9 \%)$ & \\
\hline $1-2$ & $270(38.4 \%)$ & $226(38.9 \%)$ & $44(36.1 \%)$ & \\
\hline$>2$ & $109(15.5 \%)$ & $76(13.1 \%)$ & $33(27 \%)$ & \\
\hline
\end{tabular}

Data are units (percentages) or mean (standard deviation) unless otherwise indicated

${ }^{\text {a }}$ Acute Kidney Injury was defined according to the KDIGO criteria

${ }^{b}$ Excessive alcohol use was defined as $>7$ units of alcohol for women per week and $>14$ unites of alcohol for men per week

Abbreviations: ' $A S A$ The American Society of Anaesthesiologists physical status classification; ${ }^{\mathrm{d}} q S O F A$ quick Sepsis Related Organ Failure Assessment, ${ }^{e} e G F R$ estimated Glomerular Filtration Rate, COPD ${ }^{f}$ Chronic Obstructive Pulmonary Disease

adjusted hazard ratios (HR) with 95\% CI. In the multivariable logistic regression and the multivariable survival analysis, a maximum of 1 variable per 10 events were included to avoid overfitting of the model. Statistics were performed in SPSS statistical Software version 25. IBM. USA and SAS version 9.4 (SAS institute, USA). A two-sided $P$-value $<0.05$ was considered statistically significant.

\section{Results}

1,288 potentially eligible patients underwent major emergency abdominal surgery in the study period from January 2010 to September 2016. Of these, 546 patients were excluded since no baseline s-creatinine assessment was available and another 39 patients were excluded due to missing postoperative s-creatinine levels, leaving 703 eligible patients, Fig. 1. 
Table 2 Perioperative characteristics

\begin{tabular}{|c|c|c|c|c|}
\hline & $\begin{array}{l}\text { Total } \\
(n=703)\end{array}$ & $\begin{array}{l}\text { Patients without acute } \\
\text { kidney injury } \\
(n=581)\end{array}$ & $\begin{array}{l}\text { Patients with acute } \\
\text { kidney injury } \\
(n=122)\end{array}$ & $\begin{array}{l}P \text {-value } \\
\text { (acute kidney injury }^{a} \\
\text { versus no acute kidney } \\
\text { injury }^{\mathrm{a}} \text { ) }\end{array}$ \\
\hline Type of surgery & & & & 0.31 \\
\hline Upper Gastrointestinal & $45(6.4 \%)$ & $33(5.7 \%)$ & $12(9.8 \%)$ & \\
\hline Small intestine with resection & $162(23.0 \%)$ & $129(22.2 \%)$ & $33(27.0 \%)$ & \\
\hline Colon with resection & $109(15.5 \%)$ & $90(15.5 \%)$ & $19(15.6 \%)$ & \\
\hline Laparotomy & $318(45.2 \%)$ & $268(46.1 \%)$ & $50(41.0 \%)$ & \\
\hline Combined small intestine and colon & $50(7.1 \%)$ & $44(7.6 \%)$ & $6(4.9 \%)$ & \\
\hline Other & $19(2.7 \%)$ & $17(2.9 \%)$ & $2(1.6 \%)$ & \\
\hline Peritoneal contamination & & & & $<0.0001$ \\
\hline None & $440(62.7 \%)$ & $377(65.0 \%)$ & $63(51.6 \%)$ & \\
\hline Minimal & $107(15.2 \%)$ & $91(15.7 \%)$ & $16(13.1 \%)$ & \\
\hline Local pus/abscess & $60(8.5 \%)$ & $52(9.0 \%)$ & $8(6.6 \%)$ & \\
\hline Diffuse pus or faeces & 95 (13.5\%) & $60(10.3 \%)$ & $35(28.7 \%)$ & \\
\hline Peroperative blood loss & & & & 0.84 \\
\hline$<100 \mathrm{ml}$ & $558(88.7 \%)$ & $454(88.5 \%)$ & $104(89.7 \%)$ & \\
\hline $100-500 \mathrm{ml}$ & $49(7.8 \%)$ & $40(7.8 \%)$ & $9(7.8 \%)$ & \\
\hline$>500 \mathrm{ml}$ & $22(3.5 \%)$ & $19(3.7 \%)$ & $3(2.6 \%)$ & \\
\hline Missing & $74(10.5 \%)$ & $68(11.7 \%)$ & $6(4.9 \%)$ & \\
\hline Peroperative blood transfusion & $31(4.4 \%)$ & $23(4.0 \%)$ & $8(6.6 \%)$ & 0.19 \\
\hline $\begin{array}{l}\text { Transferred directly to the ICU postopera- } \\
\text { tively (on POD 0) }\end{array}$ & $53(7.5 \%)$ & $31(5.3 \%)$ & $22(18.0 \%)$ & $<0.001$ \\
\hline s-Creatinine $\left(\boldsymbol{\mu m o l} \mathrm{I}^{-1}\right)$, Median (IQR) & $79(40)$ & $77(34)$ & $93(50)$ & $<0.0001$ \\
\hline eGFR $\left[\mathrm{ml}\left(\min 1.73 \mathrm{~m}^{2}\right)^{-1}\right]$, Median $(\mathrm{IQR})^{\mathrm{e}}$ & $65(32)$ & $68(29.5)$ & $58(29.5)$ & $<0.0001$ \\
\hline Missing & $219(31.2 \%)$ & & & \\
\hline Blood Urea (mmol I-1), Median (IQR) & $6.9(5.1)$ & $6.7(4.8)$ & $8.8(6.1)$ & $<0.0001$ \\
\hline Missing & $61(8.7 \%)$ & & & \\
\hline p-sodium (mmol I-1), Median (IQR) & $137(5.0)$ & $137(5.0)$ & $136(6.0)$ & 0.18 \\
\hline Missing & $25(3.6 \%)$ & & & \\
\hline p-potassium (mmol I-1), Median (IQR) & $3.7(0.6)$ & $3.7(0.6)$ & $3.6(0.8)$ & 0.26 \\
\hline Missing & $28(4.0 \%)$ & & & \\
\hline p-haemoglobin $\left(\mathrm{mmol} \mathrm{I}^{-1}\right)$, Median (IQR) & $8.5(1.9)$ & $8.5(1.8)$ & $8.4(1.8)$ & 0.16 \\
\hline Missing & $35(5.0 \%)$ & & & \\
\hline
\end{tabular}

Data are units (percentages) or mean (standard deviation) unless otherwise indicated

${ }^{\text {a }}$ Acute Kidney Injury was defined according to the KDIGO criteria. Biochemical parameters were assessed preoperatively

Patient demographics and clinical characteristics are presented in Tables 1 and 2. One hundred and twentytwo of the 703 patients (17.4\%) suffered AKI within postoperative day seven. Patients with AKI were significantly older, were more likely to be smoking, presented with lower performance scores and a higher ASA class and CCI. Looking at separate comorbidities, patients with AKI were more likely to suffer from hypertension and diabetes, Table 1. Patients with AKI had a higher qSOFA score at admission. Significantly more patients with AKI had intraoperative peritoneal contamination compared with patients without AKI (48.4\% (59/122) versus 35.0\% $(203 / 581), P<0.0001)$.

\section{Acute kidney injury and $\mathrm{s}$-Creatinine changes}

Seventy-one of the 122 patients (58.2\%) with postoperative AKI developed their kidney injury at postoperative day 1, Fig. 2. S-creatinine returned to baseline for $48.0 \%$ of the patients with AKI within postoperative day 7. Of the 122 patients that developed postoperative AKI, 82 (67.2\%) had AKI stage 1, 26 (21.3\%) had AKI stage 2, and $14(11.5 \%)$ had AKI stage 3. Patients with AKI had a 


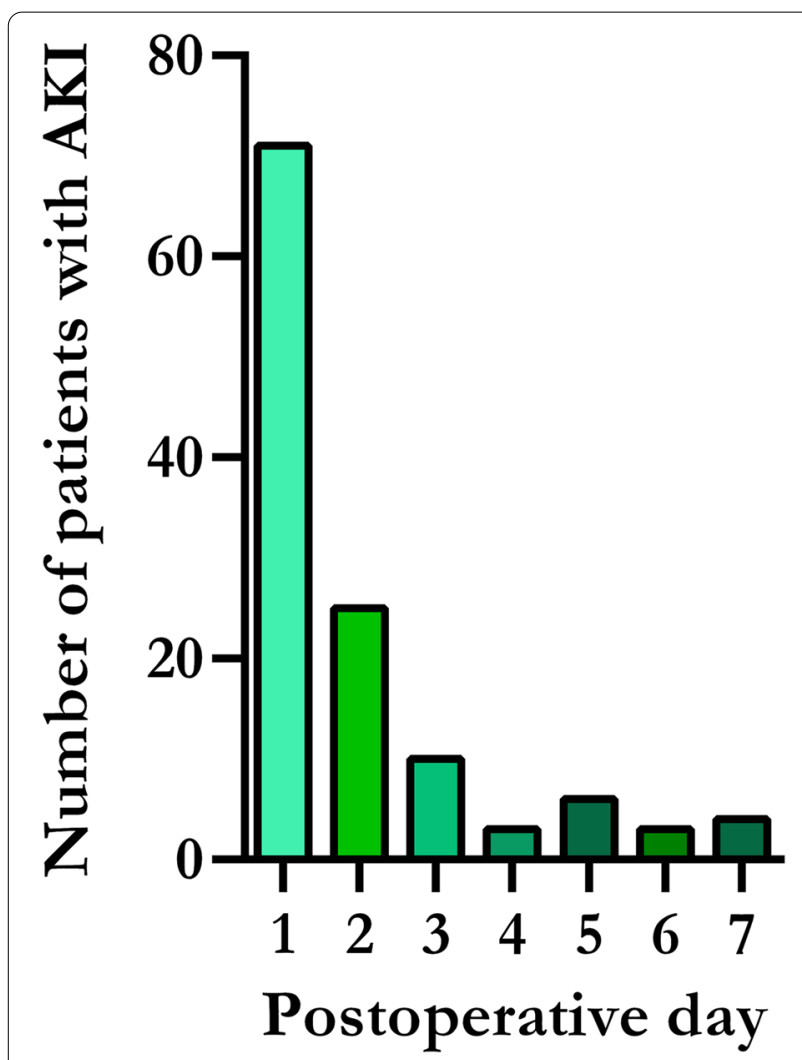

Fig. 2 The occurrence of postoperative acute kidney injury. The figure illustrates on which postoperative day patients met the acute kidney injury criteria

significantly higher s-creatinine during the postoperative period compared with patients without AKI, $P<0.0001$, Fig. 3.

\section{Unadjusted clinical outcomes}

The overall 30-day and 90-day mortality were $8.7 \%$ (61/703 patients) and $11.5 \%$ (81/703 patients), respectively. Thirty-day and 90-day mortality were significantly higher in patients with postoperative AKI compared with patients without postoperative AKI (27.9\% (34/122 patients) versus $4.7 \%$ (27/581 patients), $P<0.0001$ and $33.6 \%$ (41/122 patients) versus 6.9\% (40/581 patients), $P<0.0001$, respectively). Moreover, 90-day mortality increased significantly with increasing KDIGO stage, $P<0.0001$, as illustrated in Fig. 4 .

More patients with AKI were admitted to the ICU compared with patients without AKI (36.1\% (44/122 patients) versus $11.9 \%(69 / 581$ patients $), P<0.0001)$. Stratified on KDIGO stage, $61.4 \%$ (27/44 patients) of the patients admitted to the ICU with AKI had AKI stage 1, 18.2\% (8/44 patients) had AKI stage 2, and 20.4\% (9/44 patients) had AKI stage $3, P=0.064$. Likewise, length of stay was significantly increased in patients with AKI compared with patients without AKI [17 days (IQR 10-27) versus 8 days (IQR 5-14), $P<0.0001$ ]. Patients with AKI were more likely to suffer a surgical complication during hospital admission compared with patients without AKI (83/122 patients $(68.0 \%)$ versus $166 / 581$ patients $(28.6 \%)$, $P<0.0001)$. All clinical outcomes stratified on KDIGO stages are presented in Table 3.

\section{Adjusted clinical outcomes}

In the multivariable logistic regression, pre-existing hypertension and intraoperative peritoneal contamination were independently associated with the risk of postoperative AKI, Table 4.

Table 5 displays uni- and multivariable 90-day survival analyses. Postoperative AKI was significantly associated with an increased 90-day mortality, adjusted HR 4.45 (95\% CI 2.69-7.39), $P<0.0001$.

\section{Discussion}

In this retrospective cohort study, we found that $122 / 703$ (17.4\%) of patients undergoing major emergency abdominal surgery developed AKI within seven days of surgery. AKI primarily occurred within $24 \mathrm{~h}$ of surgery and only

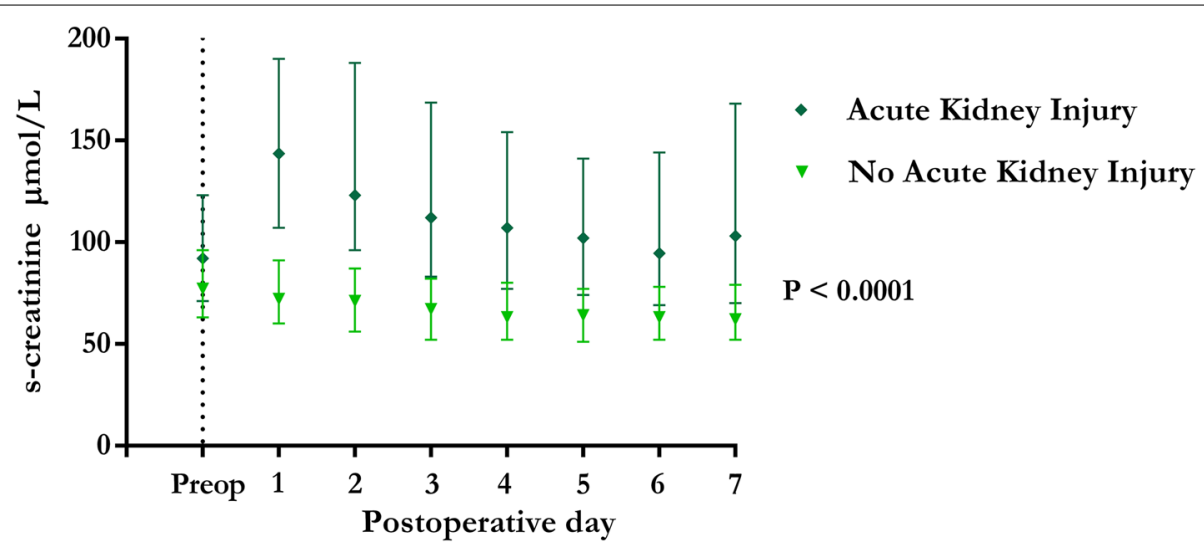

Fig. 3 s-Creatinine level in the perioperative period in patients with and without acute kidney injury 


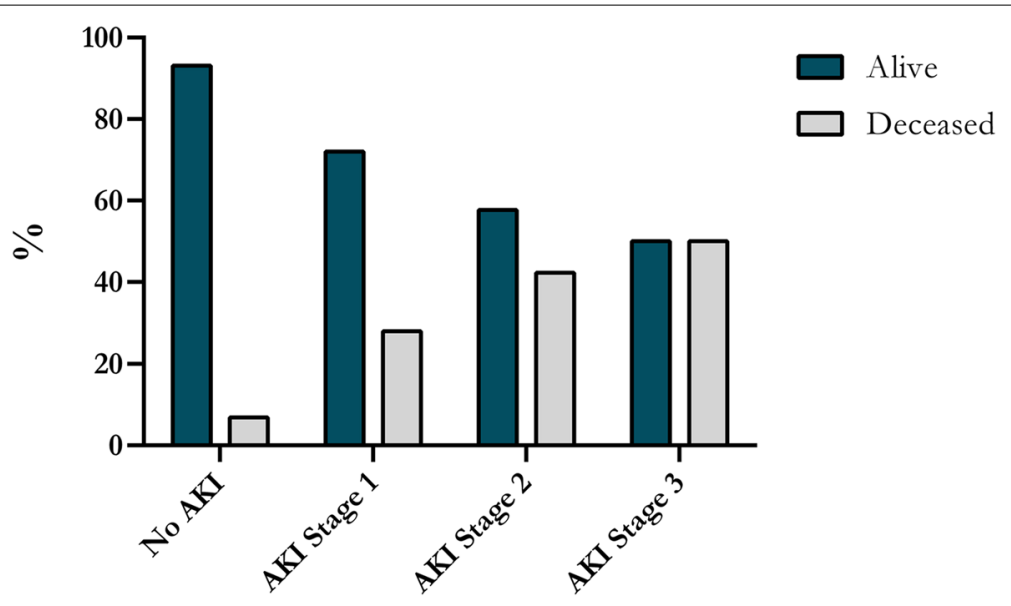

Fig. 4 90-day mortality stratified on KDIGO stage

Table 3 Clinical outcomes stratified on KDIGO stage

\begin{tabular}{|c|c|c|c|c|c|c|}
\hline & $\begin{array}{l}\text { Total } \\
(n=703)\end{array}$ & $\begin{array}{l}\text { No AKI } \\
(n=581)\end{array}$ & $\begin{array}{l}\text { AKI stage } 1 \\
(n=82)\end{array}$ & $\begin{array}{l}\text { AKI stage } 2 \\
(n=26)\end{array}$ & $\begin{array}{l}\text { AKI stage } 3 \\
(n=14)\end{array}$ & $P$-value \\
\hline 90-day mortality & 81 (11.5\%) & $40(6.9 \%)$ & $23(28.0 \%)$ & $11(42.3 \%)$ & $7(50 \%)$ & $<0.001$ \\
\hline $\begin{array}{l}\text { Surgical complica- } \\
\text { tions }\end{array}$ & $132(18.8 \%)$ & 107 (18.4\%) & $19(23.2 \%)$ & $2(7.7 \%)$ & $4(28.6 \%)$ & 0.26 \\
\hline $\begin{array}{l}\text { Length of stay, } \\
\text { Median (IQR) }\end{array}$ & $9(11)$ & $8(9)$ & $15(18)$ & $22(15)$ & $18(8)$ & $<0.001$ \\
\hline ICU admission & $113(16.1 \%)$ & 69 (11.9\%) & 27 (32.9\%) & $8(30.8 \%)$ & $9(64.3 \%)$ & $<0.001$ \\
\hline
\end{tabular}

Data are units (percentages) or mean (standard deviation) unless otherwise indicated

one in two patients with AKI had a normalised s-creatinine level on day seven after surgery. AKI was independently associated with an increased risk of 90-day mortality. Increasing age, previous hypertension and intraoperative peritoneal contamination were independently associated with the risk of postoperative AKI.

In elective surgery, the incidence of AKI ranges from $5.3 \%$ to $6.3 \%[24,25]$. This is considerably lower than the incidence of AKI in our cohort of surgical high-risk patients. We found that the patients that developed AKI were older, had a higher s-creatinine and blood urea at admission, and more commonly suffered from hypertension and diabetes. These findings suggest that the patients that develop AKI after major emergency abdominal surgery already before surgery had an affected kidney function, however, not to a point where this became clinically significant. Furthermore, intraoperative intraperitoneal severe contamination was a potent risk factor for development of AKI. This points towards a septic and inflammatory component partaking. The pathophysiology of postoperative AKI is complex and multifactorial
[26]. Major direct causes are believed to be kidney hypoperfusion, ischaemia and inflammation [25, 27], all of which may arise due to the surgically induced stress response and sepsis $[28,29]$. Consequently, patients that developed AKI had a higher qSOFA score at admission indicating that sepsis may be one of the central players in this population. However, the observational nature of our study does not permit conclusions on cause-effect relationships.

Fluid balance is essential for the perfusion of the kidneys and is largely disturbed in patients with sepsis and abdominal pathology such as small bowel obstruction [30, 31]. Perioperative fluid, hemodynamic management and risk of AKI is a much-debated topic in perioperative medicine [32]. A large multicentre randomised clinical trial on restrictive versus liberal fluid therapy in major elective abdominal surgery found the incidence of AKI, renal replacement therapy and surgical site infection to be significantly reduced in the liberal fluid group compared with the restrictive [33]. Other studies have examined the use of per- and postoperative goal-directed 
Table 4 Uni- and multivariable logistic regression on the risk of acute kidney injury

\begin{tabular}{|c|c|c|c|c|}
\hline & $\begin{array}{l}\text { Unadjusted OR } \\
(95 \% \mathrm{Cl})\end{array}$ & $P$-value & $\begin{array}{l}\text { Adjusted OR } \\
(95 \% \mathrm{Cl})\end{array}$ & $P$-value \\
\hline Baseline $\mathrm{s}$-creatinine, $\mu \mathrm{mol} \mathrm{I}^{-1}$ & $1.97(1.33-2.90)$ & 0.0007 & $1.35(0.81-2.25)$ & 0.25 \\
\hline Age group & & $<0.0001$ & & 0.10 \\
\hline$<60$ years & 1.00 (ref) & & 1.00 (ref) & \\
\hline$>60-70$ years & $3.86(2.07-7.18)$ & & $2.18(1.00-4.75)$ & \\
\hline$>70-80$ years & $3.50(1.85-6.63)$ & & $1.99(0.88-4.47)$ & \\
\hline$>80$ years & $5.54(2.93-10.48)$ & & $2.87(1.22-6.72)$ & \\
\hline Female & $0.94(0.63-1.39)$ & 0.74 & $1.04(0.61-1.78)$ & 0.89 \\
\hline Performance score & & 0.03 & & 0.70 \\
\hline 0 & 1.00 (ref) & & 1.00 (ref) & \\
\hline 1 & $1.78(1.13-2.80)$ & & $1.24(0.67-2.29)$ & \\
\hline$\geq 2$ & $1.73(0.84-3.55)$ & & $1.41(0.51-3.85)$ & \\
\hline Heart Failure & $1.50(0.66-3.40)$ & 0.33 & $0.70(0.23-2.12)$ & 0.53 \\
\hline Hypertension & $3.70(2.42-5.65)$ & $<0.0001$ & $2.90(1.65-5.10)$ & 0.0002 \\
\hline Diabetes & $2.07(1.20-3.58)$ & 0.009 & $1.81(0.89-3.69)$ & 0.10 \\
\hline Peritoneal Contamination & & $<0.0001$ & & 0.004 \\
\hline None & 1.00 (ref) & & 1.00 (ref) & \\
\hline Minimal & $1.05(0.58-1.91)$ & & $1.02(0.50-2.09)$ & \\
\hline Local pus/abscess & $0.92(0.42-2.03)$ & & $0.78(0.29-2.10)$ & \\
\hline Diffuse pus or faeces & $3.49(2.13-5.73)$ & & $2.99(1.58-5.64)$ & \\
\hline Peroperative blood loss & & 0.71 & & 0.55 \\
\hline$<100 \mathrm{ml}$ & 1.00 (ref) & & 1.00 (ref) & \\
\hline $100-500 \mathrm{ml}$ & $1.07(0.52-2.20)$ & & $0.90(0.37-2.19)$ & \\
\hline$>500 \mathrm{ml}$ & $0.55(0.12-2.42)$ & & $0.30(0.03-2.70)$ & \\
\hline qSOFA & & 0.02 & & 0.51 \\
\hline 0 & 1.00 (ref) & & 1.00 (ref) & \\
\hline 1 & $1.68(1.04-2.71)$ & & $1.36(0.76-2.42)$ & \\
\hline$\geq 2$ & $2.56(1.25-5.24)$ & & $1.49(0.65-3.41)$ & \\
\hline
\end{tabular}

95\% Cl 95\% confidence interval, OR odds ratio, a $q$ SOFA quick Sepsis Organ Failure Assessment. The multivariable logistic regression was adjusted for baseline s-creatinine, age, sex, performance score, heart failure, hypertension, diabetes, peritoneal contamination, peroperative blood loss and quick Sepsis Organ Failure Assessment score

fluid therapy, intraoperative standardised management of hypotension and targeted oliguria reversal as strategies to prevent AKI [34-36]. However, the effects of these strategies on preventing AKI are still being debated. In our cohort, the perioperative fluid administration was not standardised, and goal-directed fluid therapy was not applied.

In our study, we found that postoperative AKI was independently associated with overall 90-days mortality. This confirms findings from previous studies on patients undergoing non-cardiac surgery $[2,6]$. It is then important to consider whether AKI is a cause of mortality or if $\mathrm{AKI}$ is a symptom and consequence of underlying severe acute illness leading to single and multiorgan dysfunction. We found that almost $60 \%$ of the patients that developed AKI did so within the first $24 \mathrm{~h}$ of surgery. AKI may potentially be used as an early marker of underlying acute systemic illness or surgical complications. The predictive value of AKI needs to be confirmed in future studies.

In our study, we found that only $48 \%$ of AKI-patients had normalised s-creatinine levels within seven days of surgery. It is therefore reasonable to consider whether short-term postoperative AKI could potentially lead to a chronic kidney injury [37]. A cohort study including 390 patients undergoing urgent or elective major non-vascular abdominal surgery found that $47 \%$ of the patients that developed postoperative AKI experienced long term adverse renal outcomes $(P<0.0001)$, defined as the need for long-term dialysis and/or a $25 \%$ decrease in eGFR after hospital discharge [38]. Thus, even if AKI is a consequence of underlying acute illness, it may also be associated with long term adverse outcomes. 
Table 5 90-days uni- and multivariable survival analysis

\begin{tabular}{|c|c|c|c|c|}
\hline & $\begin{array}{l}\text { Unadjusted HR } \\
(95 \% \mathrm{Cl})\end{array}$ & $P$-value & $\begin{array}{l}\text { Adjusted HR } \\
(95 \% \mathrm{Cl})\end{array}$ & $P$-value \\
\hline Acute Kidney Injury & $5.19(3.35-8.03)$ & $<0.0001$ & $4.45(2.69-7.39)$ & $<0.0001$ \\
\hline Baseline $s$-creatinine, $\mu \mathrm{mol} \mathrm{I}^{-1}$ & $2.77(1.92-3.98)$ & $<0.0001$ & $2.20(1.35-3.59)$ & 0.002 \\
\hline Age group & & $<0.0001$ & & $<0.0001$ \\
\hline$<60$ & 1.00 (ref) & & 1.00 (ref) & \\
\hline$>60-70$ & $3.39(1.32-8.74)$ & & $1.53(0.52-4.49)$ & \\
\hline$>70-80$ & $8.55(3.57-20.45)$ & & $6.23(2.37-16.38)$ & \\
\hline$>80$ & $9.37(3.88-22.63)$ & & $5.16(1.92-13.89)$ & \\
\hline Female & $1.30(0.83-2.03)$ & 0.25 & $1.18(0.72-1.95)$ & 0.43 \\
\hline Charlson Comorbidity Index & & $<0.0001$ & & 0.001 \\
\hline 0 & 1.00 (ref) & & 1.00 (ref) & \\
\hline $1-2$ & $2.88(1.60-5.17)$ & & $2.64(1.37-5.07)$ & \\
\hline$>2$ & $5.58(3.02-10.31)$ & & $4.37(2.17-8.81)$ & \\
\hline Type of Surgery & & 0.06 & & 0.10 \\
\hline Upper gastrointestinal & 1.00 (ref) & & 1.00 (ref) & \\
\hline Small intestine with resection & $0.52(0.25-1.07)$ & & $0.60(0.27-1.31)$ & \\
\hline Colon with resection & $0.57(0.26-1.24)$ & & $0.91(0.37-2.27)$ & \\
\hline Laparotomy (no resection) & $0.34(0.17-0.68)$ & & $0.39(0.18-0.88)$ & \\
\hline $\begin{array}{l}\text { Combined small intestine and } \\
\text { colon }\end{array}$ & $0.48(0.18-1.30)$ & & $1.29(0.45-3.67)$ & \\
\hline Other & $0.21(0.026-1.59)$ & & $0.44(0.06-3.53)$ & \\
\hline Peritoneal Contamination & & 0.002 & & 0.35 \\
\hline None & 1.00 (ref) & & 1.00 (ref) & \\
\hline Minimal & $1.45(0.77-2.72)$ & & $1.35(0.69-2.65)$ & \\
\hline Local pus/abscess & $1.83(0.88-3.79)$ & & $1.63(0.73-3.63)$ & \\
\hline Diffuse pus or faeces & $2.83(1.67-4.80)$ & & $1.26(0.621-2.54)$ & \\
\hline qSOFA ${ }^{a}$ & & 0.04 & & 0.18 \\
\hline 0 & 1.00 (ref) & & 1.00 (ref) & \\
\hline 1 & $1.01(0.60-1.70)$ & & $0.95(0.56-1.62)$ & \\
\hline$\geq 2$ & $2.28(1.15-4.50)$ & & $1.90(0.92-3.93)$ & \\
\hline
\end{tabular}

95\% Cl 95\% confidence interval, HR Hazard ratio, ref reference level, ${ }^{a} \mathrm{q} S O F A$, quick Sepsis Organ Failure Assessment. The multivariable survival analysis was adjusted for acute kidney injury, baseline s-creatinine, age, sex, Charlson Comorbidity Index, type of surgery, peritoneal contamination, and quick Sepsis Organ Failure Assessment score

\section{Strengths and limitations}

The study is limited by its observational nature leaving a risk for residual confounding. Potential eligible patients were excluded due to missing baseline s-creatinine level. This could potentially have introduced a selection bias; however, we were not able to identify a systematic cause that could explain the missing data. Baseline s-creatinine was defined as the admission assessment. Potentially, the admission s-creatinine could already be elevated leaving a risk of underestimating the total (pre- and postoperative) occurrence of AKI. However, the focus of the study was to estimate the effect of the surgical procedure including the surgically induced stress-response on the risk of AKI, therefore, the difference in s-creatinine pre- versus post-surgery was the primary assessment of interest. We chose the highest preoperative s-creatinine value as baseline if multiple values were available to be sure not to include patients with a sole preoperative AKI. Patients were defined as having postoperative AKI if they met the KDIGO criteria postoperatively regardless of whether the damage started before or after surgery. We were unable to comment on whether a patient has AKI at admission. Moreover, we used the KDIGO Guidelines to identify cases of postoperative AKI in the cohort. However, we did not have access to urine output data, and we might have missed some cases of AKI. The study was limited by its single centre design and the results may not be generalisable. The results should be confirmed in a larger population including more centres. According to the electronic medical records, $4.3 \%$ of the population had chronic kidney disease. The prevalence of chronic 
kidney disease in other European countries were estimated to $5.4-6.2 \%$ and higher among elderly and individuals with hypertension, diabetes, or cardiovascular disease [39-41]. A substantial part of the patients in our study might have had undiagnosed chronic kidney disease since many were elderly with hypertension or diabetes. Therefore, chronic kidney disease as a risk factor for acute kidney injury cannot with certainty be assessed in this study. Another limitation was a lack of standardisation of the perioperative fluid administration in the cohort and the fact that goal-directed fluid therapy was not applied. Furthermore, we did not have data on intraoperative hypotension. The study was reported according to international guidelines and all analyses were predefined including the variables in the multivariable analyses.

\section{Conclusions}

In conclusion, one in five patients had postoperative AKI after major emergency abdominal surgery and AKI occurred within few days of the surgical procedure. The presence of AKI significantly increased the risk of death within 90 days of surgery. The pathophysiology of AKI should be further studied to develop preventive perioperative strategies.

\begin{abstract}
Abbreviations
AKI: Acute Kidney Injury; POD7: Postoperative day seven; KDIGO: Kidney Disease: Improving Global Outcomes; STROBE: The Strengthening the Reporting of Observational Studies in Epidemiology ASA: American Association of Anaesthesiologists classification; qSOFA: Quick Sequential Organ Failure Assessment; CCl: Charlson Comorbidity Index; eGFR: Estimated glomerular filtration rate; ICU: Intensive care unit; SD: Standard deviation; IQR: Interquartile range; OR: Odds ratio; 95\% Cl: 95\% Confidence interval; HR: Hazard ratio.
\end{abstract}

\section{Supplementary Information}

The online version contains supplementary material available at https://doi. org/10.1186/s12882-022-02708-8.

Additional file 1.

\section{Acknowledgements}

Preliminary data for this study were presented as an oral presentation at the Danish Surgical Society's annual gathering, October $30^{\text {th }}$ to November $1^{\text {st }}$ 2019, Copenhagen.

\section{Authors' contributions}

TBM: analysis and interpretation of data, drafting of the work. AES: analysis of data, critical revision of the work. JOO: acquisition of data, critical revision of the work. IG: concept and design, critical revision of the work. JB: concept and design, acquisition of data, critical revision of the work. SE: concept and design, acquisition of data, analysis of data, critical revision of the work. All authors approve of the final work and take public responsibility for it.

\section{Funding}

None.

\section{Availability of data and materials}

Authors had full access to all data. The datasets used and/or analysed during the current study are available from the corresponding author on reasonable request.

\section{Declarations}

\section{Ethics approval and consent to participate}

The study was approved by the Danish Data Protection Agency (approval: REG-010-2017). In Denmark, a written informed consent and ethical approval are by law not necessary for retrospective database studies. Authors had full access to all data.

\section{Consent for publication}

Not applicable.

\section{Competing interests}

The authors declare that they have no competing interests.

Received: 14 September 2021 Accepted: 18 February 2022

Published online: 05 March 2022

\section{References}

1. Long TE, Helgason D, Helgadottir S, Palsson R, Gudbjartsson T, Sigurdsson $\mathrm{GH}$, et al. Acute kidney injury after abdominal surgery: incidence, risk factors, and outcome. Anesth Analg. 2016;122(6):1912-20.

2. O'Connor ME, Hewson RW, Kirwan CJ, Ackland GL, Pearse RM, Prowle JR. Acute kidney injury and mortality 1 year after major non-cardiac surgery. Br J Surg. 2017:104(7):868-76.

3. Briggs A, Havens JM, Salim A, Christopher KB. Acute kidney injury predicts mortality in emergency general surgery patients. Am J Surg. 2018;216(3):420-6.

4. Demarchi AC, de Almeida CT, Ponce D, e Castro MC, Danaga AR, Yamaguti FA, et al. Intra-abdominal pressure as a predictor of acute kidney injury in postoperative abdominal surgery. Renal Failure. 2014;36(4):557-61.

5. Teixeira C, Rosa R, Rodrigues N, Mendes I, Peixoto L, Dias S, et al. Acute kidney injury after major abdominal surgery: a retrospective cohort analysis. Crit Care Res Pract. 2014;2014:132175.

6. Wu HC, Wang WJ, Chen YW, Chen HH. The association between the duration of postoperative acute kidney injury and in-hospital mortality in critically ill patients after non-cardiac surgery: an observational cohort study. Ren Fail. 2015;37(6):985-93.

7. Fuhrman DY, Kellum JA. Epidemiology and pathophysiology of cardiac surgery-associated acute kidney injury. Curr Opin Anaesthesiol. 2017;30(1):60-5.

8. O'Neal JB, Shaw AD, Billings FTt. Acute kidney injury following cardiac surgery: current understanding and future directions. Crit Care (London, England). 2016;20(1):187.

9. Biteker M, Dayan A, Tekkesin Al, Can MM, Tayci I, Ilhan E, et al. Incidence, risk factors, and outcomes of perioperative acute kidney injury in noncardiac and nonvascular surgery. Am J Surg. 2014;207(1):53-9.

10. Kellum JA, Lameire N, Aspelin P, Barsoum RS, Burdmann EA, Goldstein SL, et al. Kidney disease: Improving global outcomes (KDIGO) acute kidney injury work group KDIGO clinical practice guideline for acute kidney injury. Kidney Int Suppl. 2012;2(1):1-138.

11. Kellum JA, Lameire N. Diagnosis, evaluation, and management of acute kidney injury: a KDIGO summary (Part 1). Crit Care (London, England). 2013;17(1):204

12. Peacock O, Bassett MG, Kuryba A, Walker K, Davies E, Anderson I, et al. Thirty-day mortality in patients undergoing laparotomy for small bowel obstruction. Br J Surg. 2018;105(8):1006-13.

13. Straatman J, Cuesta MA, de Lange-de Klerk ES, van der Peet DL. Longterm survival after complications following major abdominal surgery. J Gastrointestinal Surg. 2016;20(5):1034-41.

14. Desborough JP. The stress response to trauma and surgery. $\mathrm{Br} J$ Anaesth. 2000;85(1):109-17. 
15. Oreskov JO, Burcharth J, Nielsen AF, Ekeloef S, Kleif J, Gögenur I. Quality of recovery after major emergency abdominal surgery: a prospective observational cohort study. Minerva Chir. 2020;75(2):104-10.

16. Saunders DI, Murray D, Pichel AC, Varley S, Peden CJ. Variations in mortality after emergency laparotomy: the first report of the UK Emergency Laparotomy Network. Br J Anaesth. 2012;109(3):368-75.

17. Tengberg LT, Bay-Nielsen M, Bisgaard T, Cihoric M, Lauritsen ML, Foss NB. Multidisciplinary perioperative protocol in patients undergoing acute high-risk abdominal surgery. Br J Surg. 2017;104(4):463-71.

18. von Elm E, Altman DG, Egger M, Pocock SJ, Gotzsche PC, Vandenbroucke JP. The Strengthening the Reporting of Observational Studies in Epidemiology (STROBE) Statement: guidelines for reporting observational studies. Int J Surg (London, England). 2014;12(12):1495-9.

19. Charlson M, Szatrowski TP, Peterson J, Gold J. Validation of a combined comorbidity index. J Clin Epidemiol. 1994;47(11):1245-51.

20. Dindo D, Demartines N, Clavien PA. Classification of surgical complications: a new proposal with evaluation in a cohort of 6336 patients and results of a survey. Ann Surg. 2004;240(2):205-13.

21. Kheterpal S, Tremper KK, Heung M, Rosenberg AL, Englesbe M, Shanks AM, et al. Development and validation of an acute kidney injury risk index for patients undergoing general surgery: results from a national data set. Anesthesiology. 2009;110(3):505-15.

22. Abelha FJ, Botelho M, Fernandes V, Barros H. Determinants of postoperative acute kidney injury. Critical care (London, England). 2009:13(3):R79.

23. Romagnoli S, Ricci Z. Postoperative acute kidney injury. Minerva Anestesiol. 2015;81(6):684-96.

24. Park YS, Jun IG, Go Y, Song JG, Hwang GS. Comparison of acute kidney injury between open and laparoscopic pylorus-preserving pancreaticoduodenectomy: Propensity score analysis. PloS one. 2018;13(8):e0202980.

25. Sun LY, Wijeysundera DN, Tait GA, Beattie WS. Association of intraoperative hypotension with acute kidney injury after elective noncardiac surgery. Anesthesiology. 2015;123(3):515-23.

26. Ostermann M, Liu K. Pathophysiology of AKI. Best Pract Res Clin Anaesthesiol. 2017:31(3):305-14.

27. Wang Y, Bellomo R. Cardiac surgery-associated acute kidney injury: risk factors, pathophysiology and treatment. Nat Rev Nephrol. 2017:13(11):697-711.

28. Alazawi W, Pirmadjid N, Lahiri R, Bhattacharya S. Inflammatory and immune responses to surgery and their clinical impact. Ann Surg. 2016;264(1):73-80.

29. Finnerty CC, Mabvuure NT, Ali A, Kozar RA, Herndon DN. The surgically induced stress response. JPEN J Parenter Enteral Nutr. 2013;37(5 Suppl):21s-s29.

30. Yuki K, Murakami N. Sepsis pathophysiology and anesthetic consideration. Cardiovasc Hematol Disord: Drug Targets. 2015;15(1):57-69.

31. Pironi L. Definitions of intestinal failure and the short bowel syndrome. Best Pract Res Clin Gastroenterol. 2016;30(2):173-85.

32. Miller TE, Pearse RM. Perioperative fluid management: moving toward more answers than questions-a commentary on the RELIEF study. Perioperative Med (London, England). 2019;8:2.

33. Myles PS, Bellomo R, Corcoran T, Forbes A, Peyton P, Story D, et al. Restrictive versus Liberal Fluid Therapy for Major Abdominal Surgery. N Engl J Med. 2018;378(24):2263-74.

34. Egal M, Erler NS, de Geus HR, van Bommel J, Groeneveld AB. Targeting oliguria reversal in goal-directed hemodynamic management does not reduce renal dysfunction in perioperative and critically ill patients: a systematic review and meta-analysis. Anesth Analg. 2016;122(1):173-85.

35. Giglio M, Dalfino L, Puntillo F, Brienza N. Hemodynamic goal-directed therapy and postoperative kidney injury: an updated meta-analysis with trial sequential analysis. Crit Care (London, England). 2019;23(1):232.

36. Futier E, Lefrant JY, Guinot PG, Godet T, Lorne E, Cuvillon P, et al. Effect of individualized vs standard blood pressure management strategies on postoperative organ dysfunction among high-risk patients undergoing major surgery: a randomized clinical trial. JAMA. 2017;318(14):1346-57.

37. Hobson C, Ruchi R, Bihorac A. Perioperative acute kidney injury: risk factors and predictive strategies. Crit Care Clin. 2017;33(2):379-96.

38. Gameiro J, Neves JB, Rodrigues N, Bekerman C, Melo MJ, Pereira M, et al. Acute kidney injury, long-term renal function and mortality in patients undergoing major abdominal surgery: a cohort analysis. Clin Kidney J. 2016:9(2):192-200.
39. Gasparini A, Evans M, Coresh J, Grams ME, Norin O, Qureshi AR, et al. Prevalence and recognition of chronic kidney disease in Stockholm healthcare. Nephrol Dial Transplant. 2016;31(12):2086-94.

40. Hirst JA, Hill N, O'Callaghan CA, Lasserson D, McManus RJ, Ogburn E, et al. Prevalence of chronic kidney disease in the community using data from OxRen: a UK population-based cohort study. Br J Gen Pract. 2020;70(693):e285-93.

41. Zdrojewski L, Zdrojewski T, Rutkowski M, Bandosz P, Krol E, Wyrzykowski $B$, et al. Prevalence of chronic kidney disease in a representative sample of the Polish population: results of the NATPOL 2011 survey. Nephrol Dial Transplant. 2016;31(3):433-9.

\section{Publisher's Note}

Springer Nature remains neutral with regard to jurisdictional claims in published maps and institutional affiliations.
Ready to submit your research? Choose BMC and benefit from:

- fast, convenient online submission

- thorough peer review by experienced researchers in your field

- rapid publication on acceptance

- support for research data, including large and complex data types

- gold Open Access which fosters wider collaboration and increased citations

- maximum visibility for your research: over $100 \mathrm{M}$ website views per year

At BMC, research is always in progress.

Learn more biomedcentral.com/submissions 